\title{
Improving Cloud Learning System using Technology Acceptance Model
}

\author{
Kristiawan Nugroho \\ AMIK Jakarta Teknologi Cipta \\ Jl. Kelud Raya No 19 \\ Semarang, Indonesia
}

\author{
Sugeng Murdowo \\ AMIK Jakarta Teknologi Cipta \\ Jl.Kelud Raya no 19 \\ Semarang, Indonesia
}

\author{
Sumardi \\ AMIK Jakarta Teknologi Cipta \\ JI.Kelud Raya no 19 \\ Semarang, Indonesia
}

\begin{abstract}
Learning to use information technology is a new learning trend as an alternative model of manual learning that knows so far. Some universities use elearning in their learning process, however because of increasing elearning file storage capacity used, Universities must provide infrastructure in the form of hardware with good specifications which of course requires high investment costs. Cloud computing is an information technology service that can be accessed by customers through computer resources connected to the internet. This mechanism allows users to rent information technology resources such as infrastructure and storage via the internet, Institutions can save IT investment because using this technology. This paper is explain about the implementation of learning technology using cloud computing approach called Cloud Learning System (CLS). CLS is hoped can help the learning process become more efficient, especially for institutions that will implement learning models online with the internet without having to invest in providing infrastructure in the learning system for students. This research used Technology Acceptance Model (TAM) to evaluate the results of student acceptance of the Cloud Learning System. The evaluation results using TAM indicate the level of user acceptance, the results of Confidence, Complexity, Time Limits, Usability, Ease of Use, and Behavioral Intention jointly influence the use of Cloud Learning System with F count> F table $(11,625 .>2,42)$.
\end{abstract}

\section{Keywords}

E-learning, Infrastructure, Cloud, Learning, System, TAM

\section{INTRODUCTION}

The development of information and communication technology in the field of education is increasing from year to year. Nowadays more and more university institutions complete their learning facilities by using information technology. One of them is the use of elearning which is a means of learning where lecturers and students can interact online in conducting lectures. elearning is a means of education that includes self-motivation, communication, efficiency, and technology. Because there is to the limit in social interaction, students must keep themselves motivated. Elearning is a learning activity utilizing information transfer and knowledge utilization using computer-based technology [1]. The development of information technology today that increasingly require fast information access and high computer infrastructure cause not all higher education institutions can implement elearning well. The growth of elearning data, especially data in the form of multimedia files and video requires storage and good computer specifications to access it. This problem causes the institution must issue high investment in providing computer facilities and network to be able to run elearning optimally.
Cloud computing is a form of information technology development, Cloud computing is a technology of using computing resources as a service over the network [2], By using Cloud Computing user can hire service resources in the form of platforms, infrastructures, and software to cause an institution must spend a large investment in building infrastructure, especially servers and clients, because they can subscribe to facilities already provided by the Cloud System. Cloud Learning technology can be implemented in several universities in Indonesia. The use of distance learning technology in accordance with government policy in designing a model of learning that can be done by many people whenever and wherever so that the same learning quality can be obtained by all students in Indonesia. However online learning is not without problems. Research conducted on a group of students in Egypt shows that they tend to have a negative attitude toward the use of online learning, do not consider online learning as easy to use, do not feel the usefulness of online learning, and even they intend not to using online learning [3].Because of Cloud Learning System, its expected that the online learning model of college will be better, besides not having to spend high investment, lecturers and students will be more eager in doing online learning activities because of the system designed according to their needs, where lecturers can deliver all materials and students can interact in online learning better.

The use of Cloud Computing in the learning process is a new paradigm in the world of Education in Indonesia. Cloud Computing (CC) provides benefits to academics and students to make $\mathrm{CC}$ an attractive choice in higher education [4]. Cloud Computing technology applied in the world of education. Students can communicate with lecturers and academics better, Students can access the system for learning wherever they are, Students can also access and store online learning results with large files such as multimedia files and learning videos. Cloud Computing have 3 architecture services, namely Infrastructure (IaaS), Platform (PaaS) and Software (SaaS). The SaaS CC model allows users to access software over the Internet at low cost. Thus CC allows users to use applications without having to install and run applications on a computer [5]. The lowest layer of infrastructure Cloud computing is hardware or referred to as the Infrastructure as a Service (IAAS) and the highest level of cloud computing architecture is the application layer. This layer consists of actual applications from the cloud where the types of services can be directly sent or used by end users. In general, the type of delivery service delivered through this layer is called Software as a Service (SaaS). The architectural drawings of Cloud Computing are shown in Figure 1 as follows. 


\section{Cloud Computing}

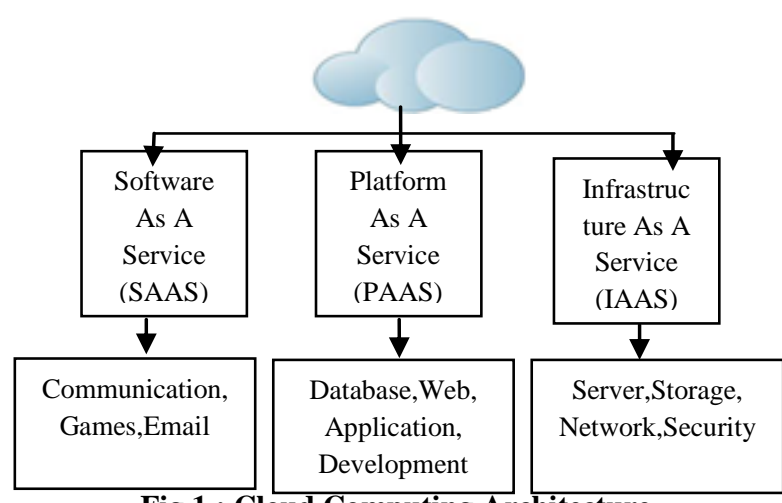

Fig 1 : Cloud Computing Architecture

Some educational institutions have felt the significant benefits of Cloud Computing technology development and save the financial, operational, maintenance, management, and administrative expenses faced [6]. Cloud computing implementation cause major investments in IT equipment procurement within an institution can be reduced and more importantly that with cloud computing technology will bring many benefits, especially in education. The benefits of learning with cloud learning to be gained are easy and fast accessibility, saving time and cost, modular, broad participation, can accommodate different learning styles and levels [7]. Otherwise in addition to the positive advantages of learning with Cloud Learning also has some disadvantages, in addition to requiring active participation from both students and lecturers, learning with Cloud Learning to be inefficient because of low motivation of users of this system to use Cloud Learning resulting in the system does not provide positive results as described previously.

\section{LITERATURE REVIEW}

Distance learning is a method implemented in university learning,This learning model is known as elearning. Gotschall described distance learning as a broadcast of lectures to distant locations, usually through video presentations[8]. Callan et al[9] and Garrison[10] identified many advantages for elearning technologies including:

1. Elearning It's cheaper, affordable, and saves.

2. More flexible to use. In other words because elearningallows students to access material from anywhere at any time.

3. Provide access to global resources and material to meet the interests and level of knowledge and students.

4. Elearning is more effective for interactions between students and instructors through the use of e-mail, discussion boards and chat rooms.

5. Students have abilities in the development of their progress.

6. Elearning helps students increase knowledge using the latest technology and the Internet.

7. elearning can improve the quality of learning and the teaching process because it still supports the face-to-face teaching approach

This paper used TAM (Technology Acceptance Model) in evaluating Cloud Learning Systems. Research using the Technology Acceptance Model framework was conducted by
Taher Farahat [11] in 2012 at the University in Egypt, the result of which students 'perceptions of ease of use, attitudes toward online learning, and social influences of referral group students were identified as significant determinants of students' intention to practice online learning. The advantage of using TAM according to Jogianto [12] are:

1 TAM is a model of behavior that is useful behavio to answer the question of why many systemsinformation technology failed to apply because of the Wearer do not have the intention to use it.

2 The most important advantage of TAM is this model is a parsimony model that is a model simple but valid.

3 TAM has been tested with a lot of research and results most support and conclude that TAM is a good model.

4 TAM is built on a strong theoretical basis.

\section{METHOD}

This paper used Technology Acceptance Model (TAM) method, TAM is a model used to measure the level of user acceptance of a new system. This model captures the practical and psy-chological implications of receiving new information systems [13]. TAM developed by Davis in 1989 is a model used to predict acceptance of a newly applied technology. At present, TAM is one of the most important theoretical contributions to the acceptance and use of an information system. the TAM model is shown in figure 2 .

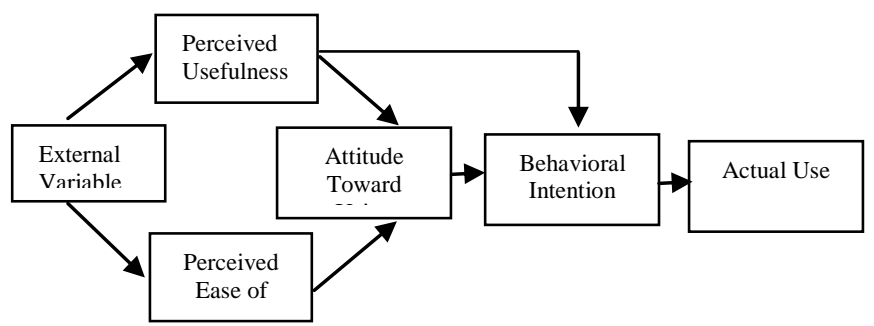

Fig 2 : Technology Acceptance Model

This model illustrates that information system users will be influenced by variable usefulness and ease of use, both of which have high determinants and validity that has been empirically tested. Davis defines the perception of perceived of usefulness based on the definition of useful words, namely capable of being used advantageously, or can be used for profitable purposes. Perception of usability is a benefit that individuals believe can be obtained when using IT. Potential users believe that certain applications are useful, maybe they, at the same time, believe that this system is too difficult to use and the benefits obtained from use that exceeds the effort to use the application. That is, in addition to the benefits or uses, the application of information technology systems will also be influenced by perceived ease of use. Therefore Davis added the two components to the TAM model.

\section{RESULT AND DISCUSSION}

\subsection{Use Case Design}

The Cloud Learning System design used the Unified Modeling Language (UML), UML is a language that is used to specify, visualize, build and document parts of information used for the process of making software The design of the use case diagram in the Cloud Learning System is shown in the picture as below: 


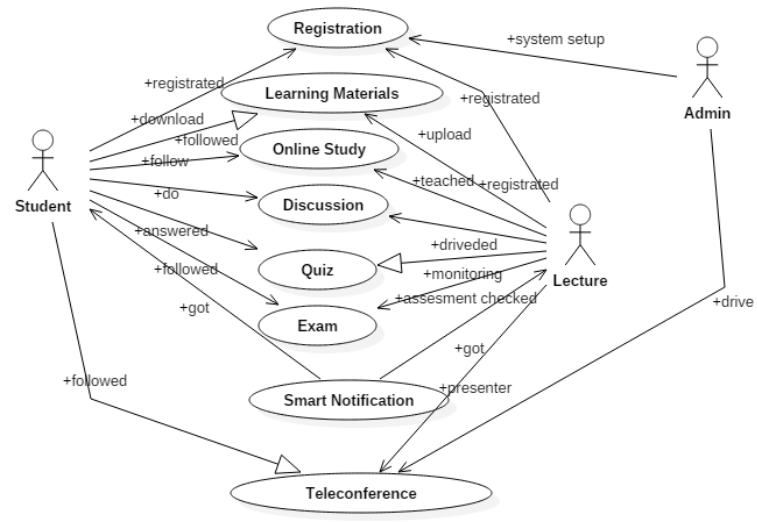

Fig 3 : The UML of Cloud Learning System

UML's figure above shows the relationship between the actor Students, Lecturers and Admin in interacting in the learning process through Cloud Learning System. Students and Lecturers interact online in teaching and learning process, while admin role as data regulator needed in this electronic learning. One of the leading features in the CLS is the smart notification that plays a tool in providing information on a regular basis to both lecturers and students in the learning process, with this notification lecturers and students will be more active in learning using CLS, while other features that are not less important Teleconference where lecturers and students are also biased to do learning through online video so that will be more interactive in learning through CLS.

\subsection{User Interface Web Pages}

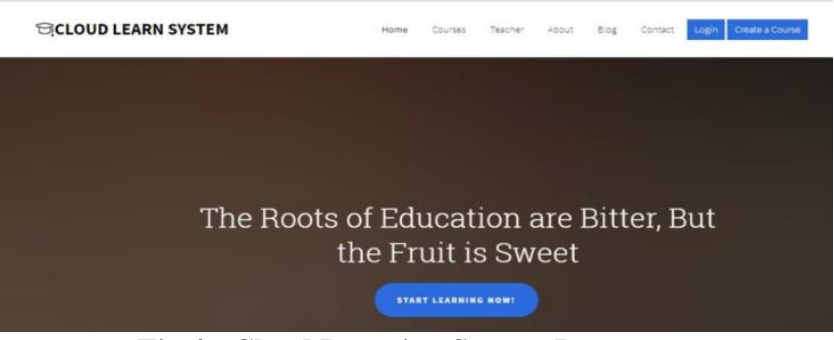

Fig 4 : Cloud Learning System Page

Figure 4 above is the main page Cloud Learning System where users can login to get into the dashboard system. Only registered users in the database can login in the CLS.



Fig 5 : Cloud Learning System Dashboard

Figure 5 is a CLS dashboard menu where faculty and students can interact in learning using every menu available in the dashboard. Every available menu depends on the permissions of each user in CLS.

\subsection{Validity Test}

The reserach uses data of 30 student respondents who have run CLS, The measurement result is described as follows:

a. Measurement Validity Test

Validity indicates the extent to which the measuring tool is able to measure what it wants to measure. In testing the validity using Pearson Correlation technique, where the process is seen from the correlation value at the total value of the answer. The values in the answer row are compared with $r$ table with a significance value of $5 \%$ and the sample number of 30 rtables is 0.361 . The test results are valid if rcount> from rtabel, from the research variables there is 1 variable declared invalid.

b. Reliability of Measuring Instruments Test Reliability test is used to determine the consistency of measuring instruments that usually use the questionnaire. Reliability test is a continuation of the validity test where the items included in the test is a valid item only. By using the limit 0.6 can be known whether the instrument is reliable or not. With less than 0.6 is less good, for a value of 0.7 is acceptable and above 0.8 is good.

Table 1. The Results Reliability Test

\begin{tabular}{|c|c|c|c|}
\hline No & Variable & $\begin{array}{l}\text { CronBach's } \\
\text { Alpha }\end{array}$ & $\begin{array}{l}\mathrm{N} \text { Of } \\
\text { Items }\end{array}$ \\
\hline 1 & Confidence (X1) & 0.933 & 2 \\
\hline 2 & Complexity (X2) & 0.665 & 3 \\
\hline 3 & $\begin{array}{l}\text { Time Limitations } \\
\text { (X3) }\end{array}$ & 0.694 & 2 \\
\hline 4 & Usefulness (X4) & 0.854 & 6 \\
\hline 5 & Convenience (X5) & 0.832 & 6 \\
\hline 6 & $\begin{array}{l}\text { Behavioral intent } \\
\text { (X6) }\end{array}$ & 0.869 & 5 \\
\hline 7 & Usage $(\mathrm{Y})$ & 0.700 & 6 \\
\hline
\end{tabular}

Source: Primary Data Processing Results SPSS Ver 17

\subsection{The Regression Coefficient Together Test(F Test)}

Regression test is jointly used to determine the effect of together dependent variable $(\mathrm{X})$ on the dependent variable (Y). F test results can be seen in Table 2 as follows:

Table 2. F Test Result



Source: Primary Data Processing Results SPSS Ver 17 
a. Predictors (Independent): Confidence, Hassle, TimeLimitations, Usability, Ease of Use, Behavioral Intent.

b. Dependent Variable: The real use.

Based on $F$ test results from the above table using the significance level of 0.05 and df 1 (number of variables -1) and df $2(n k-1)$ or $30-6-1$ (where $n=$ number of respondents, $\mathrm{k}=$ number of independent variables) is read from the table $\mathrm{F}$ of 2.42. For test criteria if $\mathrm{F}$ arithmetic $<\mathrm{F}$ table, then Ho is accepted and If Fcount $>\mathrm{F}$ table then Ho is rejected.

From $\mathrm{F}$ test result obtained Fcount equal to 8,805 , then Fcount> Ftable (11.625> 2.42), then Ho rejected. So it can be concluded that Confidence, Hassle, Time Limitations, Usability, Ease of Use, and Behavioral Intentions simultaneously affect the real usage.

\subsection{Partial Regression Coefficient Test ( $T$ test)}

$\mathrm{T}$ test is used to know the partial independent variable $(\mathrm{X})$ significantly influence the dependent variable $(\mathrm{Y})$. Test results $\mathrm{f}$ by using multiple linear regression can be seen in table 3 as follows:

Table 3. T Test Result

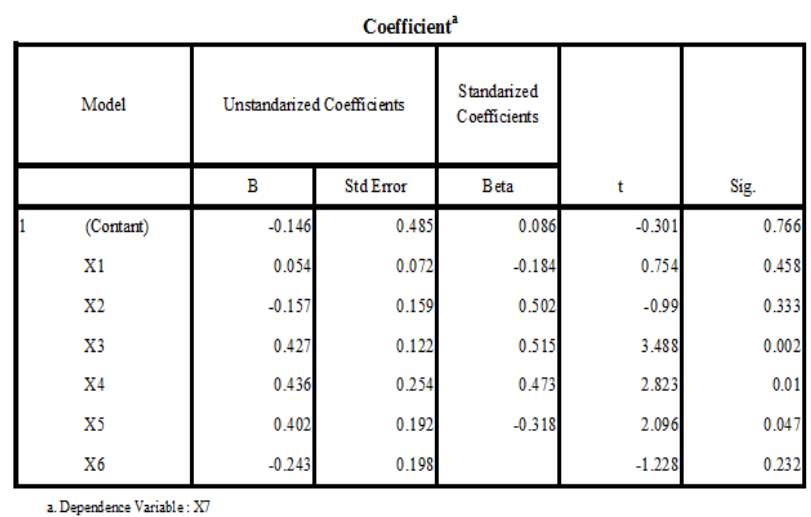

Source: Primary Data Processing Results SPSS Ver 17

a) Independent Variables

- X1 - Confidence

- X2 - Complexity

- X3 - Time Limitations

- X4 - Usefulness

- X5 - Ease of Use

- X6 - Behavioral intent

b) Dependent Variable Y (X7) - Real Use

Test criteria Test $t$ is if the value of $t$ count $>$ ttabel then $\mathrm{H} 1$ accepted and Ho rejected, and if the value $\mathrm{t}$ count <ttabel then $\mathrm{H} 1$ is processed and Ho accepted. For t table value can be seen from statistic table with significance value $0.05 / 2=0.025$ and degrees of freedom $\mathrm{df}=30-6-1=23$ is 2,042 .

Here are the results of each hypothesis:

1. Testing based on confidence variables uses that belief of use has no effect on actual use of Cloud earning System. This is evidenced by the value of $t$ count $>$ ttable $(0.754<2.042)$ which means $\mathrm{H} 1$ is rejected.
2. Tests based on complex variables that the complexity does not affect the actual use of Cloud Learning System. This is evidenced by the value of $t$ count <ttabel $(-990<2.042)$ which means $\mathrm{H} 1$ is rejected.

3. Tests based on time limit variables that time constraints affect the actual use of Cloud Learning System. This is evidenced by the value of t count> ttable $(3.488>2.042)$ which means H1 accepted.

4. Testing based on time usability variables that usability affects the actual use of Cloud Learning System. This is evidenced by the value of $t$ count $>$ ttable (2.823> 2.042) which means H1 accepted.

5. Testing based on the convenience variables that ease affect the actual use of Cloud Learning System.This is evidenced by the value $t$ count $<$ ttabel $(2.096<2.042)$ which means H1 accepted.

6. ests based on behavioral intention variable that behavior intention does not affect the actual use of Cloud Learning System. This is evidenced by the value of $\mathrm{t}$ count <ttabel $(-1.134<2.042)$ which means $\mathrm{H} 1$ is rejected

\section{CONCLUSION}

Cloud Learning System application was tested using the Technology Acceptance Model, a conclusion are:

1. Based on Test $f$ it is explained that Confidence, Complexity, Time Limitations, Usability, Ease of Use, and Behavioral Intentions together affect the real use of Cloud Learning System. can be seen from the value of $\mathrm{F}$ arithmetic $>\mathrm{F}$ table (11.625.> 2.42).

2. Based on the results of the $t$ test it can be seen thatthe Limitations of Time,Usability, and Ease togetheraffect the actual usage of Cloud Learning System. Can be seen from the value of tcount> ttable, 3.488> 2.042 for the limitations. 2.823> 2.042 for usability and 2.096> 2.042 for convenience.

\section{ACKNOWLEDGMENTS}

The authors acknowledged to Ministry of Research, Technology, and Higher Education for granted funding through Penelitian Kerjasama Perguruan Tinggi (PKPT), No: 098/K6/KM/SP2H/PENELITIAN/2018.

\section{REFERENCES}

[1] Jui Pattnayak,Sabyasachi Pattnaik,"Integration ofWeb Services with Elearning for Knowledge Society",2nd International Conference on Intelligent Computing, Communication \& Convergence,vol 92,pp.155160,2016

[2] Sharmila,Nisha Jebaseeli,"Enhancing M-Learning SystemUsing Cloud Computing",International Journal of Computer ciences and Engineering,vol 4,pp 51-55,2016.

[3] Taher Farahat," Applying the Technology AcceptanceModel to Online Learning in the Egyptian Universities",International Educational Technology Conference IETC 2012,Egypt.

[4] Abusfian Elgelany,Weam Gaoud Alghabban,"CloudComputing: Empirical Studies in Higher Education",International Journal of Advanced 
Computer Science and Applications,vol 8 pp. 121127,2017 .

[5] Y. Jadeja and K. Modi, "Cloud computing concepts,architecture and challenges," in 2012 International Conference on Computing, Electronics and Electrical Technologies (ICCEET), Kumaracoil, India, 2012, pp. 877-880.

[6] Getso, M. and Ahmed, R.,"Applications of cloudcomputing in academic institutions.",International Journal of Information Systems and Engineering, 2(1), pp. 65-72. 2014.

[7] Mansi Bosamia,Atul Patel. A An Overview of CloudComputing for Elearning With Its Key Benefits, International Journal of Information Sciences and Techniques (IJIST), vol 6 pp, India.2016.

[8] Gotschall, M.. (2000). Elearning strategies for executiveeducation and corporate training. Fortune, 141 (10) S5 - S59.
[9] Callan, V. J., Bowman, K., \& Framework, A. F. L.

2010). Sustaining Elearning Innovations: A Review of the Evidence and Future Directions: Final Report, November.

[10] Garrison, D. R. (2011). Elearning in the 21st Century: A Framework for Research and Practice. Taylor \& Francis.

[11] Taher Farahat,Applying the Technology AcceptanceModel to Online Learning in the Egyptian Universities,International Educational Technology Conference IETC 2012,Procedia - Social and Behavioral Sciences 64 ( 2012 ) 95- 104

[12] .Jogiyanto. (2007). Sistem Informasi Keperilakuan. Andi. Yogyakarta.

[13] Ahmad Samed Al-Adwan, Exploring students acceptance of elearning using Technology Acceptance Model in Jordanian universities, The International Journal of Education and Development using Information and Communication,2013 